\title{
Binge Drinking and Educational Participation among Youth in the COMPASS Host Study (Year 5: 2016/2017): School Connectedness and Flourishing as Compensatory Factors
}

\author{
Simone D. Holligan, Wei Qian, Margaret de Groh, Ying Jiang, \\ Karen A. Patte, Katelyn Battista and Scott T. Leatherdale
}

\begin{abstract}
The current study investigated resilience factors influencing the associations between binge drinking and measures of educational participation among Canadian youth. Selfreported data were collected during the 2016/2017 school year from 5238 students in Grades 9 through 12 (2744 females, 2494 males) attending 14 secondary schools in Ontario and British Columbia as part of the COMPASS study. Logistic regression analyses were conducted to determine relationships between binge drinking, school connectedness and flourishing on measures of educational participation. Binge drinking was associated with increased likelihood of skipping classes, going to class without completing homework, lower Math and English scores, and having educational and/or training expectations and aspirations beyond high school only. Decreased flourishing was linked to increased likelihood of going to class with incomplete homework, lower Math and English scores, and decreased likelihood of aspiring and expecting to achieve education and/or training beyond high school only. Increased school connectedness was associated with decreased likelihood of skipping classes and going to class with incomplete homework, higher Math and English scores, and increased the likelihood of aspiring to and expecting to achieve education and/or training beyond high school only. Lower flourishing was additive in its effect on current binge drinking in negatively impacting class attendance and homework completion and academic performance, while higher school connectedness was compensatory in its effect on these outcomes. This study suggests that, for high school students who are susceptible to binge drinking, those who are more connected to school and have a higher sense of wellbeing can maintain active participation in school and achieve their educational goals.
\end{abstract}

Keywords: adolescent, alcohol, binge drinking, academic achievement, resilience 
Dr. Simone D. Holligan conducted the current study as an NSERC Visiting Fellow at the Public Health Agency of Canada, with a cross-appointment at the University of Waterloo. She has taken a cell-to-society approach in research and policy development and has a keen interest in initiatives for improving population health. She has had the opportunity to examine key issues in the evolving fields of basic and applied health research and has written conference abstracts and publications on a number of emerging trends, including: Holligan, S. D., Battista, K., De Groh, M., Jiang, Y., Leatherdale, S. T. (2019) "Age at First Alcohol Use Predicts Current Alcohol Use, Binge Drinking and Mixing of Alcohol with Energy Drinks among Ontario Grade 12 Students in the COMPASS Host Study." Health Promotion and Chronic Disease Prevention in Canada, 39(11); Holligan, S.D., Gebauer, S.K., West, S.G., Kay, C.D., \& Kris-Etherton. (2014). "A moderate-fat diet containing pistachios improves emerging markers of cardio-metabolic syndrome in healthy adults with elevated LDL levels." British Journal of Nutrition, 112, 744-752; and Holligan, S.D., Berryman, C.E., Wang, L., Flock, M.R., Harris, K.A., \& Kris-Etherton. (2012). "Atherosclerotic cardiovascular disease." In J.W. Erdman, I.A., Macdonald \& S.H. Zeisel, (Eds.), Present knowledge in nutrition. Tenth Edition (pp. 745-805). Chichester, UK: Wiley-Blackwell.

Dr. Wei Qian is a biostatistician in the School of Public Health and Health Systems at the University of Waterloo. His work focuses on correlated data analysis, data integration, and survey design. Recent publications include: Dumitressus L, Qian, W. Rao, JNK. (2020). "Inference for longitudinal data from complex sampling surveys: an approach based on quadratic inference functions." Accepted by Scandinavian Journal of Statistics; Dumitressus L, Qian, W, Rao, JNK. (2020). "A weighted composite likelihood approach to inference from clustered survey data under a two-level model." Submitted to Sankhya A; Weatherson, K., Patte, K., Qian, W., Leatherdale, S., \& Faulkner, G. (2020). "Are one-year changes in adherence to the 24-hour movement guidelines associated with flourishing among Canadian youth?" Preventive Medicine (in press); Patte KA, Qian W, Leatherdale ST. "Predictors of one-year change in how youth perceive their weight." Journal of Obesity. Volume 2020; and Patte KA, Faulkner G, Qian W, Duncan M, Leatherdale ST. "Are one-year changes in adherence to the 24-hour Movement Guidelines associated with depressive symptoms among youth?” BMC Public Health. May, 2020.

Dr. Margaret de Groh is a Scientific Manager in the Applied Research Division, Health Promotion and Chronic Disease Prevention Branch, Public Health Agency of Canada. Her primary research focuses on enhancing innovative and multi-sectoral approaches to promote healthy living and prevent chronic disease, in particular in the area of healthy living, problematic substance use, social determinants of health, mental health, and built environment. She leads and collaborates on several national public health studies, particularly applied research and modeling activities, to understand the future disease burden, inform public health policy and program development, and broadly engage partners and stakeholders in health promotion and chronic disease prevention. Recent publications include: Chantal Lemieux, Margaret De Groh, Laurie Gibbons, Howard Morrison, Ying Jiang. (2020) "A Practical Review of the Canadian Diabetes Risk Assessment Questionnaire (CANRISK)." Canadian Journal of Diabetes. https://doi.org/10.1016/j.jcjd.2020.03.002; Alexandra Zuckermann, Mahmood Gohari, Margaret de Groh, Ying Jiang, Scott Leatherdale. (2020) "Cannabis cessation among Canadian youth: rates, patterns, and academic outcomes in a large prospective cohort of Canadian high school students." Health Promotion and Chronic Disease Prevention in Canada. April, 2020 (Vol 40:4) https://doi.org/10.24095/hpcdp.40.4.01; Simone Holligan, Wei Qian, Margaret de Groh, Ying Jiang, Scott T. Leatherdale. (2020) "Micro-Level Factors Associated with Alcohol Use and Binge Drinking Among Youth in The COMPASS Study (2012/2013 to 2017/2018)." Health Promotion and Chronic Disease Prevention in Canada. March, 2020 (Volume 40:3) https://doi.org/10.24095/hpcdp.40.3.0; Sebastian Srugo, Ying Jiang, Margaret de Groh. (2020) "Living arrangements and health status of seniors in the 2018 Canadian Community Health Survey." Health Promotion and Chronic Disease Prevention in Canada. January, 2020 (vol 40:1) https://doi.org/10.24095/hpcdp.40.1.03; and Sebastian Srugo, Margaret de Groh, Ying Jiang, Howard Morrison, Hayley Hamilton, Paul Villeneuve. (2019) "Assessing the impact of school-based greenness on mental health among adolescent students in Ontario, Canada." Int. J. Environ. Res. Public Health November, 2019, 16(22), 4364; https://doi.org/10.3390/ijerph16224364.

Dr. Ying Jiang has been working as a senior epidemiologist in the Applied Research Division, Health Promotion and Chronic Disease Prevention Branch, Public Health Agency of Canada since 2009. Her primary research interests are in the areas of population research on chronic disease prevention such as diabetes and mental condition/illness and intervention research on problematic substance use and built environment. Recent publications include: Gillian Williams, Kate Battista, Margaret de Groh, Ying Jiang, Howard Morrison, and Scott Leatherdale. (2020) "Longitudinal associations between bullying and alcohol use and binge drinking among grade 9 and 10 students in 
Holligan, Qian, de Groh, Jiang, Patte, Battista and Leatherdale

the COMPASS study." Canadian Journal of Public Health. June, 2020. https://doi.org/10.17269/s41997-02000319-0; and Sebastian Srugo, Howard Morrison, Paul Villeneuve, Margaret de Groh, Ying Jiang. (2019) "Development and comparison of a young adult-specific dysglycemia risk score to the published CANRISK." Canadian Journal of Diabetes. https://doi.org/10.1016/j.jcjd.2019.11.002

Dr. Karen Patte is an Assistant Professor in the Department of Health Sciences at Brock University. She is the Mental Health Lead (PI) and a current Co-Investigator on the COMPASS study. With training in health psychology and public health, her research explores youth mental health, focusing on the interrelationships with various health behaviours (e.g., substance use, unhealthy weight-control behaviours, sleep, physical activity, eating behaviour) and psychosocial and environmental influences (e.g, the school environment). She led the development and testing of the COMPASS Mental Health Module - a research platform designed to evaluate the real-world effectiveness of schoolbased mental health interventions. The COMPASS Mental Health project aims to build capacity and provide infrastructure to continually improve programs, policies, and resources for the promotion of youth mental health and the prevention of mental ill-health. Examples of some recent publications include: Weatherson K, Patte K, Qian W, Leatherdale ST, \& Faulkner G. "Are one-year changes in adherence to the 24-hour movement guidelines associated with flourishing among Canadian youth?" Accepted to the Journal of Preventive Medicine. June 8, 2020; Patte KA, Faulkner G, Qian W, Duncan M., Leatherdale ST. (2020) "Are one-year changes in adherence to the 24-hour movement guidelines associated with depressive symptoms among youth?" BMC Public Health. $20,739$. https://doi.org/10.1186/s12889-020-08887-z; Patte KA, Qian W, Leatherdale ST. (2020) "Predictors of one-year change in how youth perceive their weight." Journal of Obesity. https://doi.org/10.1155/2020/7396948; Romano I, Butler A, Patte KA, Ferro MA, Leatherdale ST. (2019) "High school bullying and mental disorder: an examination of the association with flourishing and emotional regulation." International Journal of Bullying Prevention. Available online August 3, 2019. https://doi.org/10.1007/s42380-019-00035-5; Romano I, Williams G, Butler A, Aleyan S, Patte K, Leatherdale ST. (2019) "Psychological and behavioural correlates of cannabis use among Canadian secondary school students: Findings from the COMPASS Study." Canadian Journal of Addiction. 10(3):10-21; Butler A, Romano I, Patte KA, Ferro MA, de Groh M, Jiang Y, Leatherdale ST. (2019) "Psychological correlates and binge drinking behaviours among Canadian youth: a cross-sectional analysis of the mental health pilot data from the COMPASS Study." BMJ Open. 9:e028558. doi:10.1136/bmjopen-2018-028558; Patte KA, Qian W, Cole AG, Faulkner G, Chaput J-P, Carson V, Leatherdale ST. (2019). "School start time changes in the COMPASS study: associations with youth sleep duration, physical activity, and screen time." Sleep Medicine. 56:16-22; and Butler A, Patte KA, Ferro M, Leatherdale ST. (2019) "Interrelationships among depression, anxiety, flourishing, and cannabis use in youth." Addictive Behaviors. 89:206-215.

Dr. Katelyn Battista is a PhD candidate in the School of Public Health and Health Systems at the University of Waterloo. She holds a Master of Mathematics degree in biostatistics from the University of Waterloo. She is employed as a Data Analyst on the COMPASS project, where she oversees dataset management and data quality for a hierarchical prospective cohort study following 75,000+ Canadian youth. Her primary research interest is in using machine learning methods to evaluate policy and program changes within large datasets. Recent publications include:Williams G, Battista K, de Groh M, Jiang Y, Morrison W, Leatherdale ST. (2020) "Longitudinal associations between bullying and alcohol use and binge drinking among grade 9 and 10 students in the COMPASS study." Canadian Journal of Public Health. https://doi.org/10.17269/s41997-020-00319-0; Doggett A, Battista K, Leatherdale ST. (2020) "Modes of cannabis use among Canadian youth in the COMPASS study; using LCA to examine patterns of smoking, vaping, and eating/drinking cannabis." Drugs: Education, Prevention and Policy, DOI: 10.1080/09687637.2020.1769560; and Zuckermann AME, Williams GC, Battista K, Jiang Y, de Groh M, Leatherdale ST. (2020). "Prevalence and correlates of youth poly-substance use in the COMPASS study." Addictive Behaviours. Volume 107; doi.org/10.1016/j.addbeh.2020.106400

Dr. Scott Leatherdale is a Professor, a CIHR-PHAC Chair in Applied Public Health Research in the School of Public Health and Health Systems, and a University Research Chair at the University of Waterloo. His work focuses on advancing a systems science approach to primary prevention activities, developing and evaluating populationlevel health interventions across multiple risk factor domains, and creating research infrastructure to facilitate large population studies in chronic disease prevention. His work is designed to engage numerous stakeholders at multiplelevels (regional, provincial, national) to impact the Canadian population. The core foundation for his current program of research is the COMPASS System; a prospective cohort study following 75,000+ Canadian youth to evaluate how ongoing and real-world changes to programs, policies, or built environment resources surrounding youth impact multiple health behaviours and outcomes over time. Dr. Leatherdale was the inaugural winner of the 
CIHR-IPPH Trailblazer Award in Population Health Solutions. Recent publications include: Doggett, A., Battista, K., Leatherdale, S.T. (2020) "Modes of cannabis use among Canadian youth in the COMPASS study; using LCA to examine patterns of smoking, vaping, and eating/drinking cannabis." Drugs: Education, Prevention \& Policy. https://doi.org/10.1080/09687637.2020.1769560; Patte, K.A., Qian, W., Leatherdale, S.T. (2020) "Predictors of oneyear change in how youth perceive their weight." Journal of Obesity. https://doi.org/10.1155/2020/7396948; Patte, K.A., Faulkner, G., Qian, W., Duncan, M., Leatherdale, S.T. (2020) "Are one-year changes in adherence to the 24hour Movement Guidelines associated with depressive symptoms among youth?" BMC Public Health. $20,739$. https://doi.org/10.1186/s12889-020-08887-z; Zuckermann, A.M.E., Gohari, M.R., de Groh, M., Jiang, Y., Leatherdale, S.T. (2020) "Cannabis cessation among youth: rates, patterns, and academic outcomes in a large prospective cohort of Canadian high school students." Health Promotion and Chronic Disease Prevention. 4, 95103. https://doi.org/10.24095/hpcdp.40.4.01; and Zuckermann, A.M.E., Williams, G., Battista, K., Jiang, Y., de Groh, M. Leatherdale, S.T. (2020) "Prevalence and correlates of youth poly-substance use within the COMPASS Study." Addictive Behaviors. 107. https://doi.org/10.1016/j.addbeh.2020.106400. 


\section{Introduction}

Reports from the Canadian Centre on Substance Abuse have shown negative impacts of alcohol consumption on the mental and physical development in youth (Butt, Beirness, Gliksman, Paradis, \& Stockwell, 2011). Binge drinking in adolescents, defined as having five or more alcohol drinks on one occasion (Wechsler \& Nelson, 2001) has been associated with lower academic performance in school and increased tendency for smoking and use of illicit substances (Miller, Naimi, Brewer, \& Jones, 2007). Data from the Youth Risk Behaviour Survey indicated that while binge drinking rates were similar among girls and boys, rates rose with increasing age and grade levels (Miller et.al., 2007). Previous work has shown negative effects of binge drinking on educational achievement among youth in the COMPASS Host Study, specifically the decreased likelihood for higher Math and English scores (Patte, Qian, \& Leatherdale, 2017a). Binge drinking during adolescence has been highly predictive of binge drinking into early adulthood (McCarty et.al., 2004), which presents a problematic life trajectory. Current social norms are such that approximately $64 \%$ of Canadian adults have reported binge drinking at least once in a year (Paradis, Demers, \& Picard, 2010).

The goal of the current investigation is to gain knowledge on youth who binge drink, from a resilience perspective, with resilience defined as an adaptation to adversity brought about by a developmental process (Fergus \& Zimmerman, 2005). Resilience is here defined with a greater emphasis on the assets and resources that an individual has at their disposal to facilitate developmental growth, and less as a static individual trait. Such an approach proposes that youth possess assets and can access resources which, either alone or in combination, can compensate for, or protect against the risks that promote binge drinking behaviour and negatively impact adolescent development and normative functioning (Fergus \& Zimmerman, 2005).

Risks for youth binge drinking have been well classified in the literature and can be grouped into factors of substance use such as smoking (Herciu, Laxer, Cole, \& Leatherdale, 2014; Tucker, Orlando, \& Ellickson, 2003)), compromised health (Deykin, Levy, \& Wells, 1987), anti-social behaviour (Alati et.al., 2014), and salient cues (Alati et.al., 2014; Grube \& Wallack, 1994). Assets that protect against youth binge drinking can be identified as factors originating from the individual themselves and can be broadly categorized into factors that include attitude (Scheier, Botvin, \& Miller, 2008), autonomy (Griffin, Botvin, Scheier, Epstein, \& Doyle, 2002; Scheier, Botvin, Griffith, \& Diaz, 1999), and school engagement (Costa, Jessor, \& Turbin, 1999; Crosnoe, Johnson, Muthen, \& Curran, 2002). Resources can be identified as factors external to the individual, but available for their access. Resources that protect against youth binge drinking can be grouped into factors that include family structure (Scheier et.al., 1999), strength of personal relationships (Stanton et.al., 2002), and school structure (Crosnoe et.al., 2002). Assets and resources may combine to influence the impact of binge drinking behaviour on functional outcomes in youth.

The COMPASS Host Study offers a comprehensive resource for hierarchical study of factors influencing health behaviours in Canadian youth. Interest in the COMPASS Host Study has been motivated in large part by high prevalence of binge drinking in students in grades 9 through 12. Data from the first cycle (2012/13) of the COMPASS study indicated that approximately $26 \%$ of respondents identified as current binge drinkers (Herciu et.al., 2014). 
Further investigations have indicated that binge drinking is predictive of lower educational achievement, preparation, and engagement in Canadian youth, which may interfere with their future life aspirations (Patte et.al., 2017a).

Previous studies have shown that school structure and school engagement are key factors influencing youth academic performance (Costa et.al., 1999; Crosnoe et.al., 2002). Higher social support from teachers and parents has also predicted higher levels of school compliance (Wang \& Eccles, 2012). Higher levels of school bonding have been shown to be associated with higher levels of subjective wellbeing (Rose, Lindsey, Xiao, Finigan-Carr, \& Joe, 2017). Work by Griffin et al. (2002) also indicated that a student's sense of wellbeing is likely linked to their academic performance. The current study seeks to determine whether factors of school connectedness and flourishing influence the associations between youth binge drinking and frequency of skipping classes, completing assigned homework, current/most recent Math and English scores, and future educational expectations and aspirations via protective or compensatory mechanisms; with flourishing as a measure of overall wellbeing. Protective factors are tested using interaction effects, while compensatory factors contribute additively to the specified outcomes after accounting for risks in the model (Fergus \& Zimmerman, 2005). Findings can inform policies and preventive programming for maladaptive alcohol use and poor academic achievement in youth.

\section{Methods}

\section{Study Description}

The COMPASS Host Study is a prospective cohort study for collection of hierarchical data from a convenience sample of secondary schools and the students in grades 9 through 12 who attend these schools. Student-level assessment of current binge drinking and other health behaviours was conducted via use of the COMPASS Student Questionnaire (Leatherdale et.al., 2014). Data for the current investigation utilized a sub-sample of students who completed the Mental Health Module during the 2016/2017 academic year. Comprehensive details on the COMPASS Host Study, including sampling and data collection procedures, are available online (www.compass.uwaterloo.ca) and in print (Leatherdale et.al., 2014).

\section{Participants}

School boards and associated schools were selected according to whether they permitted active-information, passive-consent parental permission protocols (Leatherdale et.al., 2014). Student-level assessment of alcohol use and binge drinking were conducted via the COMPASS Student Questionnaire (Leatherdale et.al., 2014), with 46957 student respondents in Year 5 (Y5:2016/2017) from Ontario, Alberta, Quebec, British Columbia and Nunavut. The current study used student-level data from the Mental Health Pilot study, a subsample of the COMPASS Host Study in Year 5: 8344 students completed the Mental Health Pilot of the COMPASS Student Questionnaire (77\% participation) at 9 schools in Ontario and 5 schools in British Columbia. Missing respondents primarily resulted due to absenteeism or free/study periods. 


\section{Measures}

To assess the frequency of skipping classes, students were asked, "In the last 4 weeks, how many classes did you skip when you were not supposed to?" Responses were grouped as No skipping for "0 classes"; and Some skipping for "1 or 2 classes" or "3 to 5 classes" or "6 to 10 classes" or "11 to 20 classes" or "More than 20 classes". To assess the frequency of not completing assigned homework, students were asked, "How often do you go to class without your homework complete?" Responses were grouped as: Seldom for "Never" or "Seldom" and Often for "Often" or "Usually". To assess educational achievement students were asked, "In your current or most recent Math course, what is your approximate overall mark?" and "In your current or most recent English course, what is your approximate overall mark?" Responses for both variables were grouped as: less than 70\%; 70-79\%; 80-89\%; and 90-100\%.

To assess the level of post-secondary education and/or training that students expect to achieve, students were asked, "What is the highest level of education you think you will get?" Responses were grouped as: High School only for "Some high school or less" or "High school diploma or graduation equivalency"; College, Trade, Vocational for "College/trade/vocational certificate"; Bachelor degree for "University Bachelor's degree"; and Graduate degree for "University Master's/PhD/law school/medical school/teachers' college degree”. To assess levels of post-secondary education and/or training students would like to achieve, students were asked, "What is the highest level of education you would like to get?" Responses were grouped as: High School only for "Some high school or less" or "High school diploma or graduation equivalency"; College, Trade, Vocational for "College/trade/vocational certificate"; Bachelor's degree for "University Bachelor's degree"; and Graduate degree for "University Master's/PhD/law school/medical school/teachers' college degree".

To assess binge drinking status, students were asked, "In the last 12 months, how often did you have 5 drinks of alcohol or more on one occasion?" Responses were grouped as: Nonbinger for "I have never done this" or "I did not have 5 or more drinks on one occasion in the last 12 months" or "Less than once a month"; and Current for "Once a month" or "2 to 3 times a month" or "Once a week" or "2 to 5 times a week". To assess current smoking status, students were asked, "On how many of the last 30 days did you smoke one or more cigarettes?" Responses were grouped as: Non-smoker for "None"; and Current smoker for "1 day" or "2 to 3 days" or "4 to 5 days" or "6 to 10 days" or "11 to 20 days" or "21 to 29 days" or "30 days (every day)".

To assess psychosocial wellbeing, students were questioned using the Flourishing Scale (Diener et.al., 2010). This scale assessed students' agreement with the following statements: "I lead a purposeful and meaningful life"; "My social relationships are supportive and rewarding"; "I am engaged and interested in my daily activities"; "I actively contribute to the happiness and well-being of others"; "I am competent and capable in the activities that are important to me"; "I am a good person and live a good life"; "I am optimistic about my future"; and "People respect me". This measure is reverse coded with higher scores indicating increased languishing and lower scores indicating increased flourishing; scores range between 8 and 40. Cronbach's $\alpha$ for this measure was 0.91 . To assess the levels of school connectedness, a six-item derived measure was used. These items assessed students' agreement with the following statements, as previously 
reported (Elton-Marshall et.al., 2011): "I feel close to people at my school"; "I feel I am part of my school"; "I am happy to be at my school"; "I feel the teachers at my school treat me fairly"; "I feel safe in my school"; and "Getting good grades is important to me". Scores range between 6 and 24, with higher scores indicating higher levels of school connectedness. Cronbach's $\alpha$ for this measure was 0.83 .

\section{Statistical Analyses}

Descriptive statistics were performed to describe the distribution of the study variables. Two-sample t-tests and Chi-square tests were conducted to examine whether study variables differed between males and females. Marginal logistic regression models were used to examine whether flourishing and school connectedness moderate the impact of binge drinking status on school engagement, educational achievement, and educational ambitions in youth. Full (with interactions) and reduced (without interactions) models were fitted for each outcome, based on resilience models described elsewhere (Fergus \& Zimmerman, 2005). Models 1 and 2 are for binary outcomes for frequency of skipping classes and for frequency of not completing homework, respectively. Models 3 and 4 are for multinomial outcomes on current/most recent Math and English scores, respectively. Models 5 and 6 are for multinomial outcomes on the level of education a student would like to achieve and the level of education a student expects to achieve, respectively. Models were controlled for grade (9 through 12), sex (male or female), ethnicity (White, Non-White) and current smoking status (Non-current or Current smoker), and accounted for within-school clustering.

All analyses were conducted using the statistical software package SAS 9.4 (Cary, NC). Marginal logistic regression models were fitted by using the SAS PROC GEE procedure with a binomial distribution and a logit function for models with a binary outcome and a generalized logit function for models with a multinomial outcome. The models for binary outcomes used an exchangeable working correlation structure based on the results of initial analyses, while the models for multinomial outcomes used an independent working correlation. Empirical standard error estimates were used to calculate confidence intervals and test statistics. Statistical significance was set at $P<0.05$.

\section{Ethics}

This study has been approved by the University of Waterloo's Office of Research Ethics (ORE \# 17264) and participating school boards.

\section{Results}

\section{Demographics}

As shown in Table 1, 40.6\% $(\mathrm{n}=1114)$ of females and 40.0\% $(\mathrm{n}=998)$ of males reported current binge drinking, while 10.7\% ( $\mathrm{n}=293)$ of females and 12.1\% ( $\mathrm{n}=301)$ of males identified as current smokers. Students reported moderate levels of flourishing with mean scores 
of 16.8 (5.9) for females and 15.7 (5.6) for males, based on the $2^{\text {nd }}$ tertile of the Flourishing Scale. Students also reported high levels of school connectedness with mean scores of 18.0 (3.2) for females and 18.3 (3.3) for males, based on the $3^{\text {rd }}$ tertile of this derived measure. Regarding school engagement, $43.0 \%(n=1180)$ of females and $39.7 \%(n=991)$ of males reported some skipping of classes, while $25.0 \%(\mathrm{n}=685)$ of females and $31.9 \%(\mathrm{n}=795)$ of males reported often going to class without completing their homework. For current/most recent Math score, $28.1 \%(\mathrm{n}=771)$ of females and $33.0 \%(\mathrm{n}=822)$ of males reported scores of less than $70 \%$. Further, $22.2 \%(n=610)$ of females and $19.4 \%(n=483)$ of males reported scores between $90 \%$ $100 \%$. For current or most recent English score, $11.9 \%(n=327)$ of females and $25.3 \%(n=632)$ of males reported scores of less than 70\%. Further, $26.6 \%(\mathrm{n}=729)$ of females and $13.0 \%(\mathrm{n}=$ 325 ) of males reported scores between $90 \%-100 \%$. In terms of educational aspirations, $55.4 \%$ (n $=1520)$ of females and $35.7 \%(n=890)$ of males aspired to a graduate degree. For levels of education students expected to achieve, $41.5 \%(\mathrm{n}=1139)$ of females and $26.5 \%(\mathrm{n}=661)$ of males reported a graduate degree.

\section{Skipping Classes and Incomplete Homework}

Results for skipping classes (Model 1) and not completing assigned homework (Model 2) are given in Table 2. Compared to students who identified as non-bingers, students who reported current binge drinking were more likely to skip classes [OR 3.39, 95\% CI: 2.93-3.92]; and were more likely to go to class with incomplete homework often [OR 1.42, 95\% CI: 1.20-1.68]. For every 1-unit decrease in flourishing there was an associated $5 \%$ increase in likelihood of going to class with incomplete homework [OR 1.05; 95\% CI: 1.04-1.06]. For every 1-unit increase in school connectedness, there was an associated $10 \%$ decrease in likelihood of skipping classes [OR 0.90, 95\% CI: 0.88-0.92], and an associated 9\% decrease in likelihood of going to class with incomplete homework often [OR $0.91,95 \%$ CI: 0.89-0.94]. There were no significant interactions between flourishing and binge drinking status, or between school connectedness and binge drinking status, on predicting likelihoods of skipping classes and not completing assigned homework.

\section{Math and English Scores}

As shown in Model 3 in Table 3, students who identified as current binge drinkers were less likely than those identifying as non-current binge drinkers to report a Math score of 90$100 \%$ [OR 0.81, 95\% CI: 0.70-0.94]; 80-89\% [OR 0.74, 95\% CI: 0.64-0.85]; or 70-79\% [OR 0.81, 95\% CI: $0.70-0.94$ ] versus a score of less than 70\%. For every 1-unit decrease in flourishing, there was an associated $2 \%$ decrease in likelihood of reporting a Math score of 90$100 \%$ [OR $0.98,95 \%$ CI: $0.97-1.00$ ] or $70-79 \%$ [OR 0.98, 95\% CI: $0.97-1.00$ ] versus a score of less than $70 \%$. Alternately, for every 1-unit increase in school connectedness, there was an associated 6\% increase in likelihood of reporting a Math score of 90-100\% [OR 1.06, 95\% CI: 1.02-1.10] or 70-79\% [OR 1.06, 95\% CI: 1.02-1.10]; and a 13\% increase in likelihood of a Math 
score between $80-89 \%$ [OR 1.13, 95\% CI: 1.09-1.17] versus less than 70\%. There were no significant interactions between flourishing and binge drinking status, or between school connectedness and binge drinking status, on predicting current/most recent Math scores.

As shown in Model 4 in Table 3, students who identified as current binge drinkers were less likely than those identifying as non-current binge drinkers to report an English score of 90$100 \%$ versus a score of less than 70\%; [OR 0.70, 95\% CI: 0.60-0.82]. For every 1-unit decrease in flourishing, there was an associated $2 \%$ decrease in likelihood of reporting an English score of 70-79\% versus less than 70\%; [OR 0.98, 95\% CI: 0.97-0.99]. Further, for every 1-unit increase in school connectedness, there was an associated $23 \%, 16 \%$ and $8 \%$ increase in likelihood of reporting an English score of 90-100\% [OR 1.23, 95\% CI: 1.18-1.29], 80-89\% [OR 1.16, 95\% CI: $1.12-1.20$ ], or $70-79 \%$ [OR $1.08,95 \%$ CI: $1.05-1.11$ ] respectively versus a score of less than $70 \%$. There were no significant interactions between flourishing and binge drinking, or between school connectedness and binge drinking, on predicting current/most recent English scores.

\section{Higher Education Aspirations and Expectations}

Results on educational aspirations (Model 5) and educational expectations (Model 6) are given in Table 4. Compared to students who identified as non-bingers, students who reported current binge drinking were more likely to aspire to graduate school [OR 1.43, 95\% CI: 1.012.01]; a Bachelor degree [OR 1.67, 95\% CI: 1.15-2.43]; or postsecondary training (college/trade/vocational) [OR 1.52, 95\% CI: 1.08-2.13] over high school only. Students who reported current binge drinking were also more likely to expect to achieve a Bachelor degree [OR 1.61, 95\% CI: 1.20-2.17]; or postsecondary training (college/trade/vocational) [OR 1.40, 95\% CI: 1.09-1.78] over high school only.

For every 1-unit decrease in flourishing, there was an associated $4 \%$ decrease in likelihood of aspiring to graduate school [OR 0.96, 95\% CI: 0.94-0.99]; or postsecondary training (college/trade/vocational) [OR 0.96; 95\% CI: 0.94-0.99] over high school only. For every 1-unit decrease in flourishing there were respective decreases of $10 \%, 6 \%$ and $6 \%$ in likelihood of expecting to achieve a graduate degree [OR 0.90, 95\% CI: 0.88-0.93]; a Bachelor's degree [OR 0.94, 95\% CI: 0.92-0.96]; or postsecondary training (college/trade/vocational) [OR 0.94, 95\% CI: 0.92-0.96] over high school only. For every 1-unit increase in school connectedness there was a $16 \%$ increase in likelihood of aspiring to a graduate degree [OR 1.16; 95\% CI: 1.09-1.22], and a 10\% increase in likelihood of aspiring to a Bachelor degree [OR 1.10; 95\% CI: 1.04-1.17] over high school only. For every 1-unit increase in school connectedness there was a $17 \%$ increase in likelihood of expecting to achieve a graduate degree [OR $1.17,95 \%$ CI: 1.11-1.24], and a 13\% increase in likelihood of expecting to achieve a Bachelor's degree [OR 1.13, 95\% CI: 1.07-1.19] over high school only. There were no significant interactions between flourishing and binge drinking, or between school connectedness and binge drinking, on predicting the level of education a student aspired to achieve, or on the level of education a student expected to achieve.

Compared to Grade 9 students, students in higher grades were more likely to aspire to a Bachelor's degree and postsecondary training $(P<0.05$ for all). Students in higher grades were 
also more likely to expect to achieve a graduate degree, a Bachelor's degree, or postsecondary training when compared to Grade 9 students $(P<0.05$ for all).

\section{Discussion}

The current study provides insight into some resilience factors influencing associations between binge drinking and measures of educational participation among youth.

Current binge drinking was associated with increased likelihood to skip classes and go to class without completing homework. Students who smoked tobacco products were also more likely to skip classes and go to class without completing their homework and were less likely to aspire to and expect to achieve postsecondary education and training over high school only. It is probable that concomitant smoking is additive alongside binge drinking to negatively impact school engagement and may further impact educational ambitions. Students with lower levels of flourishing (i.e. higher levels of languishing) were more likely to go to class without completing their homework, and less likely to aspire to or expect to achieve any level of postsecondary education or training beyond high school. Students with higher levels of school connectedness had lower likelihoods of skipping classes and going to class without completing homework. Further, increased school connectedness was associated with an increased likelihood to aspire to and expect to achieve postsecondary education over high school only. These factors contribute to a significant risk-resilience profile which may impact short-term and long-term educational achievement among youth (Hill \& Wang, 2015; Wang \& Eccles, 2012).

Decreasing flourishing in students was associated with lower self-reported Math and English scores. Being deprived of this asset contributed additively to current binge drinking in negatively impacting affecting educational outcomes, aligning with previous work (Griffin et.al., 2002). Moreover, increasing school connectedness in the sample of students was associated with higher self-reported Math and English scores for all levels. The influence of school connectedness is striking as it indicates that students may leverage this resource to better their academic performance. Previous work has shown positive associations between social support from teachers and higher levels of school compliance (Wang \& Eccles, 2012), along with positive associations between school bonding and higher levels of subjective wellbeing (Rose et.al., 2017). Given the moderate levels of flourishing and school connectedness in the current sample, it is anticipated that any improvement in these factors may effectively compensate for the effects of binge drinking behaviour on educational outcomes.

The current study shows that youth who reported current binge drinking were more likely to aspire to and expect to achieve postsecondary education and training over high school only. Previous work by Patte and colleagues (2017) has also shown that students who engaged in rare/sporadic to monthly binge were more likely to aspire to achieve a Bachelor's degree or postsecondary training over high school only (Patte et.al., 2017a). Additional study on binge drinking onset in youth has shown that, compared to students who started binge drinking in Grade 10 or earlier, students who started binge drinking in Grades 11 and 12 were more likely to aspire to a graduate degree and to expect to achieve to postsecondary training, but less likely to expect to achieve a Bachelor's degree (Patte, Qian, \& Leatherdale, 2017b). It is important to note that, unlike these previous studies (Patte et al, 2017a; Patte et.al., 2017b), the current study 
accounts for school connectedness and flourishing levels among respondents, making the consistency of these results intriguing.

The present findings of lower school participation coupled with higher educational aspirations and expectations among students who binge drink are consistent with conceptual work on the "social clock" for contested behaviours in youth. The social clock has been defined as the societal expectations on the appropriate ages for youth to experience major life events, with an individual being either "early", "late" or "on-time" (Neugarten, Moore, \& Lowe, 1965). Indeed, educational aspirations and expectations beyond high school were more likely for students in later grades. Research on parenting practices show them as indirectly influencing enrollment in post-secondary education and training (Hill \& Wang, 2015). Using a sample of Ontario adults, Paglia and Room (1998) have also shown that parents who were current users of alcohol had higher tolerance for youth alcohol use compared to those who abstained. Social norms may drive parents and guardians to emphasize completing high school and furthering education and training, while assuming a more liberal role in terms of alcohol use. It is possible that youth who experiment with binge drinking during high school may exhibit this behaviour as a rite of passage that is socially acceptable within Western society (Ievers-Landis, Greenley, Burant, \& Borawski, 2006). Such behaviour may be viewed as a life-change event marking their ability to take on more personal responsibility (Paglia \& Room, 1998), including shaping their future life goals. Further investigations that account for parents' perspective of youth alcohol use and educational participation beyond high school are warranted.

There were no interactions between flourishing and binge drinking status or school connectedness and binge drinking status on measures of educational participation. These results indicate that the asset of flourishing and the resource of school connectedness may influence the associations between binge drinking and youth educational outcomes via compensatory mechanisms rather than protective ones (Fergus \& Zimmerman, 2005). Based on a resilience framework, increasing flourishing and school connectedness may buffer the associations between binge drinking and indicators of educational participation (Fergus \& Zimmerman, 2005). Flourishing, school connectedness and binge drinking are likely associated with a latent construct that directly influences students' school engagement and their subsequent educational aspirations and expectations. Indeed, higher levels of school bonding in youth have been associated with higher levels of subjective wellbeing (Rose, Lindsey, Xiao, Finigan-Carr, \& Joe, 2017). In turn, increased levels of social support from parents and teachers have been associated with higher levels of school compliance and increased subjective valuing of learning (Wang \& Eccles, 2012). As students navigate the latter years of adolescence, they may leverage the asset of flourishing and the resource of school connectedness to improve their levels of school engagement and maintain greater educational ambitions. Future work may determine whether the factors of flourishing and school connectedness are protective over varying degrees of binge drinking frequency.

\section{Strengths and Limitations}

The current study utilized a large sample of students from schools based in two Canadian provinces (Ontario and British Columbia), providing in-depth evaluation of binge drinking and 
other health behaviours in youth. However, the cross-sectional design means that causality and sequence of events cannot be inferred. Data from the COMPASS Host Study's student questionnaire are self-reported, and though bias may have been introduced, this method provides an emic representation of students' perceived flourishing and school connectedness. The data collection procedures further limit bias by use of an active-information, passive-consent permission approach which has been found to maintain perceived anonymity, improve response rates, and minimize underreporting of antisocial behaviour (Thompson-Haile, Bredin, \& Leatherdale, 2013).

\section{Implications}

This study provides insight on youth who engage in binge drinking from a resilience perspective. Based on the current results, increasing flourishing and school connectedness in students may be useful targets for substance-use intervention programs. Efforts to provide developmental supports which maintain student confidentiality, parental autonomy, and build on school-based resources would be most promising (Hill \& Wang, 2015). Increased flourishing may be achieved by enabling students to form a positive identity, increase their self-awareness, and maintain a sense of belonging within the school environment through peer-peer and peermentor relationships, along with improved teacher support (Compton, Jackson, \& Dimmock, 2016; Fergus \& Zimmerman, 2005; Mcguire, 1961). Increased school connectedness may be achieved via clear messaging of behavioural and academic standards, and an overall personalization of the school experience for students (Catalano, Berglund, Ryan, Lonczak, \& Hawkins, 2004; Rose et.al., 2017; Wang \& Eccles, 2012).

\section{Conclusion}

The current study found that youth who binge drink had poorer educational participation in terms of skipping classes, not completing assigned homework, and lower Math and English scores, while maintaining educational expectations and aspirations beyond high school. As an asset, decreased flourishing may have an additive effect on how binge drinking negatively impacts educational participation. As a resource, increased school connectedness may compensate for the negative impact of binge drinking on educational participation. School-based efforts to improve flourishing and school connectedness may enable youth to improve their school engagement, successfully meet their educational ambitions, and develop a resilient trajectory over the long-term. 


\section{References}

Alati, R., Baker, P., Betts, K. S., Connor, J. P., Little, K., Sanson, A., \& Olsson, C. A. (2014). The role of parental alcohol use, parental discipline and antisocial behaviour on adolescent drinking trajectories. Drug and Alcohol Dependence, 134, 178-184.

Butt, P., Beirness, D., Gliksman, L., Paradis, C., \& Stockwell, T. (2011). Alcohol and health in Canada: A summary of evidence and guidelines for low-risk drinking. Canadian Centre on Substance Abuse, 1-66.

Catalano, R. F., Berglund, M. L., Ryan, J. A. M., Lonczak, H. S., \& Hawkins, J. D. (2004). Positive Youth Development in the United States: Research Findings on Evaluations of Positive Youth Development Programs. The ANNALS of the American Academy of Political and Social Science, 591(1), 98-124.

Compton, J., Jackson, B., \& Dimmock, J. A. (2016). Persuading others to avoid persuasion: Inoculation theory and resistant health attitudes. Frontiers in Psychology, 7, 122.

Costa, F. M., Jessor, R., \& Turbin, M. S. (1999). Transition into Adolescent Problem Drinking: The Role of Psychosocial Risk and Protective Factors*. Journal of Studies on Alcohol, 60(4), 480-490.

Crosnoe, R., Johnson, M. K., Muthen, L., \& Curran, P. (2002). Academic and Health-Related Trajectories in Adolescence: The Intersection of Gender and Athletics*. Journal of Health and Social Behavior, 43, 317-335.

Deykin, E. Y., Levy, J. C., \& Wells, V. (1987). Adolescent depression, alcohol and drug abuse. American Journal of Public Health, 77(2), 178-182.

Diener, E., Wirtz, D., Tov, W., Kim-Prieto, C., Choi, D. won, Oishi, S., \& Biswas-Diener, R. (2010). New well-being measures: Short scales to assess flourishing and positive and negative feelings. Social Indicators Research, 97, 143-156.

Elton-Marshall, T., Leatherdale, S. T., Manske, S. R., Wong, K., Ahmed, R., \& Burkhalter, R. (2011). Research methods of the youth smoking survey (YSS). Chronic Diseases and Injuries in Canada, 32(1), 47-54.

Fergus, S., \& Zimmerman, M. A. (2005). Adolescent resilience: A framework for understanding healthy development in the face of risk. Annual Review of Public Health, 26, 399-419.

Griffin, K. W., Botvin, G. J., Scheier, L. M., Epstein, J. A., \& Doyle, M. M. (2002). Personal competence skills, distress, and well-being as determinants of substance use in a predominantly minority urban adolescent sample. Prevention Science, 3(1), 23-33.

Grube, J. W., \& Wallack, L. (1994). Television beer advertising and drinking knowledge, beliefs, and intentions among schoolchildren. American Journal of Public Health, 84(2), 254-259. 
Herciu, A. C., Laxer, R. E., Cole, A., \& Leatherdale, S. T. (2014). A Cross-sectional Study Examining Factors Associated with Youth Binge Drinking in the COMPASS Study: Year 1 Data. Journal of Alcoholism \& Drug Dependence, 2(4), 172.

Hill, N. E., \& Wang, M.-T. (2015). From Middle School to College: Developing Aspirations, Promoting Engagement, and Indirect Pathways From Parenting to Post High School Enrollment. Developmental Psychology, 51(2), 224-235.

Ievers-Landis, C. E., Greenley, R. N., Burant, C., \& Borawski, E. (2006). Cognitive social maturity, life change events, and health risk behaviors among adolescents: Development of a structural equation model. Journal of Clinical Psychology in Medical Settings, 13(2), 107-116.

Leatherdale, S. T., Brown, S., Carson, V., Childs, R. A., Dubin, J. A., Elliott, S. J., ... Thompson-Haile, A. (2014). The COMPASS study: a longitudinal hierarchical research platform for evaluating natural experiments related to changes in school-level programs, policies and built environment resources. BMC Public Health, 14(1), 1-7.

McCarty, C. A., Ebel, B. E., Garrison, M. M., DiGiuseppe, D. L., Christakis, D. A., \& Rivara, F. P. (2004). Continuity of Binge and Harmful Drinking From Late Adolescence to Early Adulthood. Pediatrics, 114(3), 714-719.

Mcguire, W. J. (1961). Resistance to persuasion conferred by active and passive prior refutation of the same and alternative counterarguments. Journal of Abnormal and Social Psychology, 63(2), 326-332.

Miller, J. W., Naimi, T. S., Brewer, R. D., \& Jones, S. E. (2007). Binge Drinking and Associated Health Risk Behaviors Among High School Students. Pediatrics, 119(1), 76-85.

Neugarten, B. L., Moore, J. W., \& Lowe, J. C. (1965). Age Norms, Age Constraints, and Adult Socialization. American Journal of Sociology, 70(6), 710-717.

Paglia, A., \& Room, R. (1998). How Unthinkable and At What Age?: Adult Opinions about the 'Social Clock' for Contested Behaviour by Teenagers. Journal of Youth Studies, 1(3), 295314.

Paradis, C., Demers, A., \& Picard, E. (2010). Alcohol Consumption: A Different Kind of Canadian Mosaic. Canadian Journal of Public Health, 101(4), 275-280.

Patte, K. A., Qian, W., \& Leatherdale, S. T. (2017a). Binge drinking and academic performance, engagement, aspirations, and expectations: a longitudinal analysis among secondary school students in the COMPASS study. Health Promotion and Chronic Disease Prevention in Canada Research, Policy and Practice, 37(11).

Patte, K. A., Qian, W., \& Leatherdale, S. T. (2017b). Is Binge Drinking Onset Timing Related to Academic Performance, Engagement, and Aspirations Among Youth in the COMPASS Study? Substance Use and Misuse, 52(13), 1795-1800. 
Rose, T., Lindsey, M. A., Xiao, Y., Finigan-Carr, N. M., \& Joe, S. (2017). Mental Health and Educational Experiences Among Black Youth: A Latent Class Analysis. Journal of Youth and Adolescence, 46(11), 2321-2340.

Scheier, L. M., Botvin, G. J., Griffith, K. W., \& Diaz, T. (1999). Latent growth models of drug refusal skills and adolescent alcohol use. Journal of Alcohol and Drug Education, 44(3), $21-48$.

Scheier, L. M., Botvin, G. J., \& Miller, N. L. (2008). Life Events, Neighborhood Stress, Psychosocial Functioning, and Alcohol Use Among Urban Minority Youth. Journal of Child \& Adolescent Substance Abuse, 9(1), 19-50.

Stanton, B., Li, X., Pack, R., Cottrell, L., Harris, C., \& Burns, J. M. (2002). Longitudinal influence of perceptions of peer and parental factors on African American adolescent risk involvement. Journal of Urban Health, 79(4), 536-548.

Thompson-Haile, A., Bredin, C., \& Leatherdale, S. T. (2013). Rationale for using activeinformation passive-consent permission protocol in COMPASS. Compass Technical Report Series, 1(6).

Tucker, J. S., Orlando, M., \& Ellickson, P. L. (2003). Patterns and correlates of binge drinking trajectories from early adolescence to young adulthood. Health Psychology, 22(1), 79-87.

Wang, M. Te, \& Eccles, J. S. (2012). Social Support Matters: Longitudinal Effects of Social Support on Three Dimensions of School Engagement From Middle to High School. Child Development, 83(3), 877-895.

Wechsler, H., \& Nelson, T. F. (2001). Binge drinking and the American college students: What's five drinks? Psychology of Addictive Behaviors, 15(4), 287-291. 
Table 1. Demographics of high school students who participated in the Mental Health Module during Year 5 (2016/2017) of the COMPASS Host Study $(\mathrm{N}=\mathbf{5 2 3 8})$

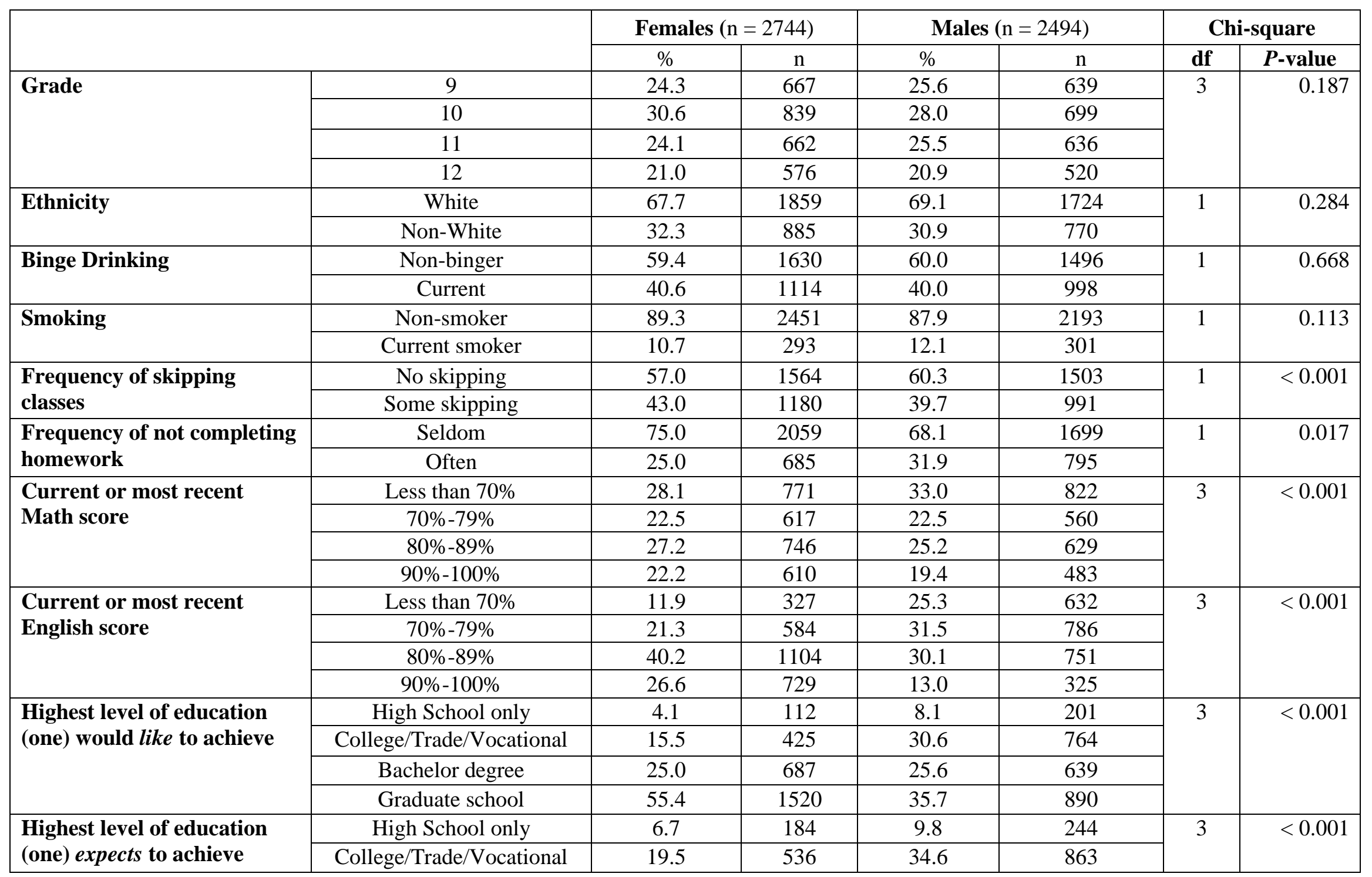


Holligan, Qian, de Groh, Jiang, Patte, Battista and Leatherdale

\begin{tabular}{|c|c|c|c|c|c|c|c|}
\hline & Bachelor degree & 32.3 & 885 & 29.1 & 726 & & \\
\hline & Graduate degree & 41.5 & 1139 & 26.5 & 661 & & \\
\hline & & & & & & & $P$-value ${ }^{\dagger}$ \\
\hline School connectedness ${ }^{\dagger}$ & Mean (CD) & & & & & - & $<0.001$ \\
\hline Flourishing ${ }^{\dagger \dagger}$ & Mean (SD) & & & & & - & $<0.001$ \\
\hline
\end{tabular}

Notes: ${ }^{\dagger}$ Scores range from 6 to $24 .{ }^{\dagger}$ Scores range from 8 to $40 .{ }^{\ddagger} P$-value for one-sample test. 
Table 2. GEE binomial logistic regression models examining moderators of the relationship between binge drinking and number of classes skipped (Model 1) and not completing homework for class (Model 2) among high school students who participated in the Mental Health Module during Year $5(2016 / 2017)$ of the COMPASS Host Study $(\mathbf{N}=5238)$.

\begin{tabular}{|c|c|c|c|c|c|c|c|c|c|}
\hline \multirow[b]{2}{*}{ Variable } & \multirow[b]{2}{*}{ Level $^{\dagger}$} & \multicolumn{4}{|c|}{$\begin{array}{c}\text { Model 1 } \\
\text { Skipping Class versus No Skipping }\end{array}$} & \multicolumn{4}{|c|}{$\begin{array}{c}\text { Model 2 } \\
\text { Not Completing Homework versus } \\
\text { Completing Homework }\end{array}$} \\
\hline & & OR & Lower & Upper & $P$-value & OR & Lower & Upper & $P$-value \\
\hline Intercept & - & 1.54 & 0.83 & 2.87 & 0.170 & 0.46 & 0.21 & 1.02 & 0.055 \\
\hline \multirow[t]{3}{*}{ Grade } & 10 & 1.16 & 0.97 & 1.39 & 0.094 & 1.17 & 0.97 & 1.40 & 0.100 \\
\hline & 11 & 1.83 & 1.42 & 2.34 & $<0.001$ & 1.45 & 1.15 & 1.82 & 0.002 \\
\hline & 12 & 2.76 & 2.12 & 3.58 & $<0.001$ & 1.27 & 0.92 & 1.75 & 0.150 \\
\hline Sex & Males & 0.89 & 0.73 & 1.08 & 0.223 & 1.58 & 1.40 & 1.77 & $<0.001$ \\
\hline Ethnicity & Non-White & 1.03 & 0.94 & 1.14 & 0.497 & 0.94 & 0.80 & 1.11 & 0.494 \\
\hline Binge Drinking & Current & 3.39 & 2.93 & 3.92 & $<0.001$ & 1.42 & 1.20 & 1.68 & $<0.001$ \\
\hline Smoking & Current & 2.91 & 2.33 & 3.63 & $<0.001$ & 1.78 & 1.36 & 2.34 & $<0.001$ \\
\hline School Connectedness & - & 0.90 & 0.88 & 0.92 & $<0.001$ & 0.91 & 0.89 & 0.94 & $<0.001$ \\
\hline Flourishing & - & 1.01 & 1.00 & 1.03 & 0.111 & 1.05 & 1.04 & 1.06 & $<0.001$ \\
\hline \multicolumn{2}{|l|}{ Concordance statistic } & & & & 0.76 & & & & 0.70 \\
\hline
\end{tabular}

Notes. $\uparrow$ Reference categories: Grade 9, Females, White, Non-binger, and Non-smoker. $\uparrow \dagger$ Interaction terms not shown. 
Table 3. GEE multinomial logistic regression models examining moderators of the relationship between binge drinking and current/most recent Math scores (Model 3) and current/most recent English scores (Model 4) among high school students who participated in the Mental Health Module during Year $5(2016 / 2017)$ of the COMPASS Host Study $(\mathbf{N}=5238)$.

\begin{tabular}{|c|c|c|c|c|c|c|c|c|c|}
\hline \multirow[b]{2}{*}{ Variable } & \multirow[b]{2}{*}{ Level $^{\dagger}$} & \multicolumn{4}{|c|}{$\begin{array}{c}\text { Model 3 } \\
\text { Math scores }\end{array}$} & \multicolumn{4}{|c|}{$\begin{array}{c}\text { Model } 4 \\
\text { English scores }\end{array}$} \\
\hline & & OR & Lower & Upper & $P$-value & OR & Lower & Upper & $P$-value \\
\hline \multicolumn{10}{|c|}{ Achieving a score of $90 \%-100 \%$ v. Less than $70 \%$} \\
\hline Intercept & & 0.43 & 0.19 & 0.97 & 0.042 & 0.06 & 0.02 & 0.21 & $<0.001$ \\
\hline \multirow[t]{3}{*}{ Grade } & 10 & 0.86 & 0.71 & 1.04 & 0.120 & 0.91 & 0.69 & 1.21 & 0.534 \\
\hline & 11 & 1.21 & 0.99 & 1.47 & 0.057 & 1.02 & 0.74 & 1.42 & 0.892 \\
\hline & 12 & 1.26 & 0.97 & 1.63 & 0.083 & 1.50 & 0.85 & 2.67 & 0.163 \\
\hline Sex & Males & 0.81 & 0.72 & 0.91 & $<0.001$ & 0.19 & 0.15 & 0.25 & $<0.001$ \\
\hline Ethnicity & Non-White & 0.93 & 0.75 & 1.15 & 0.482 & 0.88 & 0.71 & 1.10 & 0.264 \\
\hline Binge Drinking & Current & 0.81 & 0.70 & 0.94 & 0.007 & 0.70 & 0.60 & 0.82 & $<0.001$ \\
\hline Smoking & Current & 0.79 & 0.58 & 1.07 & 0.128 & 0.35 & 0.27 & 0.46 & $<0.001$ \\
\hline School Connectedness & & 1.06 & 1.02 & 1.10 & 0.002 & 1.23 & 1.18 & 1.29 & $<0.001$ \\
\hline Flourishing & $F$ & 0.98 & 0.97 & 1.00 & 0.042 & 1.01 & 0.97 & 1.04 & 0.673 \\
\hline \multicolumn{2}{|l|}{ Concordance statistic } & & & & 0.71 & & & & 0.80 \\
\hline \multicolumn{10}{|c|}{ Achieving a score of $80 \%-89 \%$ v. Less than $70 \%$} \\
\hline Intercept & & 0.20 & 0.09 & 0.44 & $<0.001$ & 0.42 & 0.19 & 0.90 & 0.026 \\
\hline \multirow[t]{3}{*}{ Grade } & 10 & 0.68 & 0.55 & 0.84 & $<0.001$ & 0.92 & 0.72 & 1.17 & 0.499 \\
\hline & 11 & 0.80 & 0.59 & 1.09 & 0.153 & 0.94 & 0.72 & 1.22 & 0.646 \\
\hline & 12 & 0.97 & 0.73 & 1.28 & 0.821 & 1.30 & 0.86 & 1.94 & 0.210 \\
\hline Sex & Males & 0.73 & 0.65 & 0.82 & $<0.001$ & 0.30 & 0.26 & 0.35 & $<0.001$ \\
\hline Ethnicity & Non-White & 1.00 & 0.76 & 1.30 & 0.974 & 0.84 & 0.69 & 1.02 & 0.080 \\
\hline Binge Drinking & Current & 0.74 & 0.64 & 0.85 & $<0.001$ & 0.99 & 0.85 & 1.16 & 0.924 \\
\hline Smoking & Current & 0.62 & 0.44 & 0.89 & 0.009 & 0.32 & 0.23 & 0.45 & $<0.001$ \\
\hline School Connectedness & & 1.13 & 1.09 & 1.17 & $<0.001$ & 1.16 & 1.12 & 1.20 & $<0.001$ \\
\hline Flourishing & & 0.99 & 0.97 & 1.01 & 0.195 & 0.99 & 0.97 & 1.01 & 0.176 \\
\hline \multicolumn{2}{|l|}{ Concordance statistic } & & & & 0.66 & & & & 0.74 \\
\hline \multicolumn{10}{|c|}{ Achieving a score of $70 \%-79 \%$ v. Less than $70 \%$} \\
\hline Intercept & & 0.43 & 0.19 & 0.97 & 0.042 & 0.75 & 0.43 & 1.30 & 0.300 \\
\hline
\end{tabular}


Holligan, Qian, de Groh, Jiang, Patte, Battista and Leatherdale

\begin{tabular}{|c|c|c|c|c|c|c|c|c|c|}
\hline Grade & 10 & 0.86 & 0.71 & 1.04 & 0.120 & 0.97 & 0.78 & 1.20 & 0.781 \\
\hline & 11 & 1.21 & 0.99 & 1.47 & 0.057 & 1.09 & 0.79 & 1.51 & 0.595 \\
\hline & 12 & 1.26 & 0.97 & 1.63 & 0.083 & 1.29 & 1.00 & 1.67 & 0.051 \\
\hline Sex & Males & 0.81 & 0.72 & 0.91 & $<0.001$ & 0.62 & 0.53 & 0.74 & $<0.001$ \\
\hline Ethnicity & Non-White & 0.93 & 0.75 & 1.15 & 0.482 & 0.90 & 0.75 & 1.07 & 0.238 \\
\hline Binge Drinking & Current & 0.81 & 0.70 & 0.94 & 0.007 & 1.09 & 0.85 & 1.39 & 0.504 \\
\hline Smoking & Current & 0.79 & 0.58 & 1.07 & 0.128 & 0.54 & 0.42 & 0.68 & $<0.001$ \\
\hline School Connectedness & & 1.06 & 1.02 & 1.10 & 0.002 & 1.08 & 1.05 & 1.11 & $<0.001$ \\
\hline Flourishing & E & 0.98 & 0.97 & 1.00 & 0.042 & 0.98 & 0.97 & 0.99 & 0.003 \\
\hline Concordance statistic & & & & & 0.60 & & & & 0.64 \\
\hline
\end{tabular}

Notes. $\dagger$ Reference categories: Grade 9, Females, White, Non-binger, and Non-smoker. $\dagger \dagger$ Interaction terms not shown. 
Table 4. GEE multinomial logistic regression models examining moderators of the relationship between binge drinking and the level of education one would like to achieve (Model 5) and the level of education one expects to achieve (Model 6) among high school students who participated in the Mental Health Module during Year $5(2016 / 2017)$ of the COMPASS Host Study (N = 5238).

\begin{tabular}{|c|c|c|c|c|c|c|c|c|c|}
\hline \multirow[b]{2}{*}{ Variable } & \multirow[b]{2}{*}{ Level $^{\dagger}$} & \multicolumn{4}{|c|}{$\begin{array}{c}\text { Model } 5 \\
\text { Like to Achieve }\end{array}$} & \multicolumn{4}{|c|}{$\begin{array}{c}\text { Model 6 } \\
\text { Expect to Achieve }\end{array}$} \\
\hline & & $\mathbf{O R}$ & Lower & Upper & $P$-value & OR & Lower & Upper & $P$-value \\
\hline \multicolumn{10}{|c|}{ College, Trade, Vocational v. High School only } \\
\hline Intercept & - & 6.03 & 1.06 & 34.20 & 0.043 & 5.00 & 1.08 & 23.18 & 0.040 \\
\hline \multirow[t]{3}{*}{ Grade } & 10 & 1.45 & 1.02 & 2.07 & 0.038 & 1.60 & 1.19 & 2.16 & 0.002 \\
\hline & 11 & 1.72 & 1.15 & 2.55 & 0.008 & 1.83 & 1.26 & 2.67 & 0.002 \\
\hline & 12 & 1.42 & 1.02 & 1.99 & 0.038 & 2.02 & 1.43 & 2.83 & $<0.001$ \\
\hline Sex & Males & 0.94 & 0.77 & 1.16 & 0.587 & 1.07 & 0.88 & 1.30 & 0.504 \\
\hline Ethnicity & Non-White & 0.73 & 0.51 & 1.04 & 0.081 & 0.79 & 0.61 & 1.03 & 0.079 \\
\hline Binge Drinking & Current & 1.52 & 1.08 & 2.13 & 0.016 & 1.40 & 1.09 & 1.78 & 0.007 \\
\hline Smoking & Current & 0.57 & 0.39 & 0.82 & 0.003 & 0.66 & 0.46 & 0.95 & 0.025 \\
\hline School Connectedness & - & 1.00 & 0.93 & 1.07 & 0.946 & 1.02 & 0.95 & 1.09 & 0.616 \\
\hline Flourishing & - & 0.96 & 0.94 & 0.99 & 0.005 & 0.94 & 0.92 & 0.96 & $<0.001$ \\
\hline \multicolumn{2}{|l|}{ Concordance statistic } & & & & 0.62 & & & & 0.65 \\
\hline \multicolumn{10}{|c|}{ Bachelor degree v. High School only } \\
\hline Intercept & - & 1.08 & 0.32 & 3.60 & 0.903 & 1.08 & 0.36 & 3.29 & 0.889 \\
\hline \multirow[t]{3}{*}{ Grade } & 10 & 1.62 & 1.12 & 2.33 & 0.010 & 1.73 & 1.28 & 2.34 & $<0.001$ \\
\hline & 11 & 2.23 & 1.53 & 3.25 & $<0.001$ & 2.02 & 1.47 & 2.78 & $<0.001$ \\
\hline & 12 & 1.94 & 1.48 & 2.56 & $<0.001$ & 2.60 & 1.87 & 3.62 & $<0.001$ \\
\hline Sex & Males & 0.46 & 0.38 & 0.57 & $<0.001$ & 0.51 & 0.41 & 0.62 & $<0.001$ \\
\hline Ethnicity & Non-White & 1.00 & 0.81 & 1.23 & 0.982 & 1.16 & 0.89 & 1.51 & 0.272 \\
\hline Binge Drinking & Current & 1.67 & 1.15 & 2.43 & 0.007 & 1.61 & 1.20 & 2.17 & 0.002 \\
\hline Smoking & Current & 0.24 & 0.15 & 0.37 & $<0.001$ & 0.25 & 0.15 & 0.43 & $<0.001$ \\
\hline School Connectedness & - & 1.10 & 1.04 & 1.17 & $<0.001$ & 1.13 & 1.07 & 1.19 & $<0.001$ \\
\hline Flourishing & - & 0.98 & 0.96 & 1.00 & 0.059 & 0.94 & 0.92 & 0.96 & $<0.001$ \\
\hline \multicolumn{2}{|l|}{ Concordance statistic } & & & & 0.71 & & & & 0.74 \\
\hline \multicolumn{10}{|c|}{ Graduate degree v. High School only } \\
\hline
\end{tabular}


Holligan, Qian, de Groh, Jiang, Patte, Battista and Leatherdale

\begin{tabular}{|l|l|r|r|r|r|r|r|r|r|}
\hline Intercept & - & 1.92 & 0.46 & 8.05 & 0.375 & 1.67 & 0.37 & 7.53 & 0.501 \\
\hline \multirow{5}{*}{ Grade } & 10 & 1.34 & 0.93 & 1.94 & 0.116 & 1.51 & 1.12 & 2.03 & 0.007 \\
\cline { 2 - 10 } & 11 & 1.30 & 0.84 & 2.03 & 0.239 & 1.60 & 1.08 & 2.38 & 0.020 \\
\cline { 2 - 10 } & 12 & 1.06 & 0.73 & 1.54 & 0.754 & 1.90 & 1.23 & 2.93 & 0.004 \\
\hline Sex & Males & 0.27 & 0.22 & 0.33 & $<0.001$ & 0.33 & 0.28 & 0.40 & $<0.001$ \\
\hline Ethnicity & Non-White & 1.17 & 0.82 & 1.67 & 0.376 & 1.13 & 0.76 & 1.69 & 0.544 \\
\hline Binge Drinking & Current & 1.43 & 1.01 & 2.01 & 0.042 & 1.35 & 0.99 & 1.85 & 0.060 \\
\hline Smoking & Current & 0.24 & 0.16 & 0.36 & $<0.001$ & 0.30 & 0.21 & 0.42 & $<0.001$ \\
\hline School Connectedness & - & 1.16 & 1.09 & 1.22 & $<0.001$ & 1.17 & 1.11 & 1.24 & $<0.001$ \\
\hline Flourishing & - & 0.96 & 0.94 & 0.99 & 0.003 & 0.90 & 0.88 & 0.93 & $<0.001$ \\
\hline Concordance statistic & - & \multicolumn{3}{|c|}{0.75} & & & \\
\hline
\end{tabular}

Reference categories: Grade 9, Females, White, Non-binger, and Non-smoker. $\uparrow \dagger$ Interaction terms not shown. 